Etnográfica

Revista do Centro em Rede de Investigação em

Antropologia

vol. 15 (1) | 2011

Vol. $15(1)$

Negociações, associações e monopólios: a política da rua em Ciudad del Este (Paraguai)

Negotiations, associations and monopolies: street politics in Ciudad del Este

(Paraguay)

\title{
Fernando Rabossi
}

\section{(2) OpenEdition}

Journals

Edição electrónica

URL: https://journals.openedition.org/etnografica/814

DOI: 10.4000/etnografica.814

ISSN: 2182-2891

Editora

Centro em Rede de Investigação em Antropologia

Edição impressa

Data de publição: 1 fevereiro 2011

Paginação: 83-107

ISSN: 0873-6561

Refêrencia eletrónica

Fernando Rabossi, «Negociações, associações e monopólios: a política da rua em Ciudad del Este (Paraguai)», Etnográfica [Online], vol. 15 (1) | 2011, posto online no dia 23 outubro 2011, consultado o 11 fevereiro 2022. URL: http://journals.openedition.org/etnografica/814 ; DOI: https://doi.org/10.4000/ etnografica.814

\section{(c) (;) (9)}

Etnográfica is licensed under a Creative Commons Attribution-NonCommercial 4.0 International License. 


\title{
Negociações, associações e monopólios: a política da rua em Ciudad del Este (Paraguai) ${ }^{1}$
}

\section{Fernando Rabossi}

\begin{abstract}
Apesar de existirem posturas municipais que regulam o comércio nas ruas de Ciudad del Este (Paraguai) e de os vendedores a elas se sujeitarem - em teoria -, a forma como se ocupa o espaço para venda nas ruas revela uma série de acordos, sedimentações e tolerâncias que estão na base de um sistema que reproduz a precariedade na qual os vendedores de rua trabalham. Ao explorar etnográfica, histórica e analiticamente as contradições entre os regulamentos formais e as formas práticas de regulação, o presente artigo procura identificar alguns mecanismos recorrentes nos processos de regularização de trabalhadores informais.
\end{abstract}

PALAVRAS-CHAVE: vendedores de rua, associações, monopólios, comércio, Paraguai, ilegalismos.

\section{AS RUAS DO CENTRO DE CIUDAD DEL ESTE, NO PARAGUAI, NÃO SÃO simplesmente lugares de circulação de pessoas e de veículos. São também um dos cenários principais da transformação dessa parte da cidade num grande mercado ao qual diariamente chegam, através da Ponte da Amizade, milha- res de compradores provenientes do Brasil. Além de carregadores, cambistas,}

l Muitos dos elementos aqui apresentados foram desenvolvidos na minha tese de doutorado em Antropologia Social, defendida em dezembro de 2004, no Programa de Pós-Graduação em Antropologia Social do Museu Nacional, Universidade Federal do Rio de Janeiro (Rabossi 2004). Uma primeira versão deste trabalho foi apresentada no simpósio "Entre o legal e o ilegal: abordagens etnográficas", realizado em outubro de 2008, no Programa de Pós-Graduação em Antropologia Social da Universidade Federal de São Carlos (Brasil), onde tive o privilégio de escutar as críticas de Jorge Mattar Villela, Lênin Pires, Antonio Rafael Barbosa e Gabriel Feltran, entre outros. Agradeço os comentários e as valiosas sugestões dos avaliadores anônimos deste artigo, assim como também os aportes e as críticas de Federico Neiburg e de Marcio Goldman recebidas ao longo da pesquisa. 
transportadores, guardas, laranjas (brasileiros dedicados à passagem de mercadorias) e compradores, milhares de vendedores oferecem seus produtos nas calçadas e ruas do centro.

O presente artigo tem por objetivo explorar como essas pessoas fazem para vender na rua. Como veremos, a venda ambulante foi perseguida nos primórdios da cidade, mas terminou sendo aceita e regulada a partir de uma série de acordos e regulamentações. Contudo, ainda que aceitas e reguladas, as práticas dos vendedores não se enquadram dentro daquilo que é definido pelas posturas municipais. Entender como e por que isto se dá nos permitirá iluminar algumas contradições inerentes aos processos de formalização de práticas informais - isto é, processos de regulamentação e regularização de categorias laborais não reconhecidas pelo Estado ou cujas práticas são realizadas fora dos marcos regulatórios estabelecidos para tanto -, contradições essas que nos permitem repensar a forma como concebemos o Estado e o funcionamento da própria lei.

Em primeiro lugar, apresentarei brevemente o universo das vendas nas ruas de Ciudad del Este. Em seguida, descreverei a instalação de uma estrutura permanente para facilitar as vendas e a distância que esta forma de ocupação mantém dos mecanismos legais. Para entender essa distância, introduzirei alguns marcos históricos na ocupação das ruas que nos permitirão entender as disjunções entre os regulamentos formais e as formas práticas de regulação. Para finalizar, à luz do material apresentado, desenvolverei algumas discussões, particularmente centradas em três assuntos: a produção de atores coletivos na interação com o Estado, a produção legal da precariedade e a relevância dessas questões para as discussões sobre segurança na região de confluência dos limites internacionais entre Brasil, Paraguai e Argentina, onde se localiza Ciudad del Este.

Antes de iniciarmos o artigo, contudo, dois esclarecimentos se fazem necessários. A chamada Tríplice Fronteira tem sido retratada como um dos espaços continentais mais críticos em termos de segurança. De fato, o projeto original que me levou à região tinha por objetivo analisar a forma como os discursos globais de segurança se localizavam em um lugar que parecia condensar todos os problemas por eles enunciados: narcotráfico, lavagem de dinheiro, pirataria, terrorismo islâmico e máfias transnacionais, dentre outros. Quando em 1999 cheguei para realizar meu trabalho de campo, contudo, o movimento comercial entre Ciudad del Este e Foz do Iguaçu se transformou no foco de minha pesquisa; não somente pela magnitude e importância que assumia para a compreensão da região, mas igualmente para a compreensão de qualquer um dos problemas apontados nestas denúncias. Assim, a presença árabe vinculada ao comércio era a condição de possibilidade das acusações sobre a presença de grupos terroristas islâmicos na região, bem como a participação de imigrantes chineses no comércio era a condição necessária para a suspeita da existência 
de máfias orientais. A enorme circulação de mercadorias e pessoas estava por trás das políticas anticontrabando e das denúncias sobre todos os tráficos ilegais. A magnitude do movimento comercial foi igualmente o que possibilitou o imenso movimento de divisas por trás das acusações sobre lavagem de dinheiro e de remessas irregulares.

Contudo, em minha pesquisa sobre o comércio de fronteira não me concentrei naquilo que aparecia recorrentemente nos meios de comunicação - narcotráfico, lavagem de dinheiro ou bens roubados, por exemplo -, mas naquilo que, caso não houvesse o limite internacional, seria simplesmente considerado um comércio como outro qualquer. Denominar as atividades que giravam em torno dos intercâmbios de produtos importados em Ciudad del Este como comerciais significou uma escolha de perspectiva, anterior às definições legais. Para quem parte, por exemplo, da definição do Estado brasileiro sobre as práticas dos compradores como "contrabando" ou "descaminho", minha posição poderia parecer hipócrita. No entanto, uma das questões-chave que quis abordar foi precisamente a relação entre determinadas atividades e suas definições; relação que, posta no espaço da fronteira, nos apresenta uma série de elementos interessantes para pensarmos sobre a natureza dessas definições e das práticas que elas comportam. A mesma questão se colocou no que diz respeito às atividades descritas como informais.

Reintroduzir estes atores e as dinâmicas a eles associadas numa discussão sobre segurança poderia parecer um contrassenso. Contudo, depois de deixar em suspenso as definições legais de muitas das práticas verificadas no comércio de Ciudad del Este para compreender o papel que tais definições assumem em sua modulação, considero fundamental trazer de volta esse "olhar de perto" para introduzir algumas ambiguidades na própria constituição da legalidade elemento-chave para reconsiderar algumas discussões contemporâneas sobre segurança.

O segundo esclarecimento diz respeito ao material apresentado a seguir. $\mathrm{O}$ artigo está baseado no trabalho de campo de quase um ano, realizado entre 1999 e 2001, na fronteira entre Brasil e Paraguai, período durante o qual morei sobretudo em Ciudad del Este. A escolha de tempos verbais no passado, no relato a seguir, reflete o interesse de frisar o momento apresentado, tornando explícita sua limitação temporal. Interessa-me enfatizar este aspecto, uma vez que muitas coisas têm mudado desde então - abordadas em outros períodos de campo, principalmente em 2006 e 2008 - e continuarão a se modificar no futuro. ${ }^{2}$ Isso não tira a validade nem a representatividade do material que

2 Três mudanças significativas que têm transformado o universo aqui descrito foram o processo de reconfiguração urbana do centro de Cuidad del Este iniciado em 2003 - que incluiu a relocalização de alguns vendedores em bancas padronizadas -; a transformação da alfândega brasileira; a denominada "lei dos sacoleiros" -, a Lei 11.898 do governo brasileiro que institui o Regime de Tributação Unificada e que visa regular pequenas importações procedentes do Paraguai. 
analiso a seguir, mas nos obriga a repensar as formas de estabilização de nossas verdades através da criação de presentes etnográficos marcadamente datados, mas pretensamente atemporais.

\section{VENDER NA RUA}

Entre os vendedores que trabalhavam nas ruas de Ciudad del Este, estavam aqueles que as percorriam com seus produtos - os ambulantes - e os que trabalhavam localizados em um lugar específico. Estes últimos eram conhecidos como mesiteros, palavra que deriva da estrutura móvel onde colocavam suas mercadorias em exibição para a venda, uma mesita - diminutivo de mesa em espanhol. Em 2001, cerca de 2000 a 3000 mesiteros trabalhavam no centro da cidade, número bem inferior ao dos anos de auge do comércio na cidade, quando eram mais de 6000, tal como registrado em um censo da Federación de Trabajadores de la Vía Pública, em 1998.

A despeito do nome, nem todos os mesiteros trabalhavam em mesitas. Muitos tinham estruturas permanentes construídas sobre a calçada: as cajas - caixas metálicas com portas, que funcionavam como suporte das mercadorias e depósito - e as casillas - boxes metálicos, que permitiam o atendimento de seu interior. Em 2001, existiam mais de 500 casillas no centro da cidade.

Diferentemente de uma loja que dia após dia abre ao público as portas de seu espaço privado, as vendas na rua são realizadas num local que não pode ser fechado após o término do dia de trabalho. De modo análogo às feiras e mercados em espaços públicos, os vendedores de rua têm de produzir diariamente o espaço para a realização de seu trabalho. Se, no caso dos vendedores localizados em lugares específicos, a produção do espaço traduz-se na montagem diária de uma estrutura para a oferta dos produtos, para aqueles que trabalham de forma ambulante, a produção desse espaço traduz-se na circulação permanente com os produtos em busca de compradores.

Esta forma de espacialização das trocas no comércio de rua corresponde àquela presente em feiras e mercados em espaços públicos, forma de espacialização esta que contrasta com as vendas em espaços fechados, tais como lojas, galerias ou shopping centers. Julgado a partir da pretensa inevitabilidade dessas formas de comercialização na modernização das cidades, o comércio de rua é percebido como uma forma pré-moderna, cuja persistente existência consiste no elemento a ser explicado - algo que se relaciona antes com ideais do que deve ser a cidade e a sociedade do que com desenvolvimentos históricos concretos, tal como parece demonstrar a proliferação do comércio de rua em tantas partes do mundo. ${ }^{3}$

3 Eis alguns títulos dentre tantos outros sobre a recorrência do comércio de rua em diversos países: para os Estados Unidos, ver Duneier (1999), Morales (2000) e Stoller (2002a, 2002b); [continua] 
Vender na rua implica produzir diariamente o espaço para as vendas. Mas como é que se ocupa esse espaço? Partindo da instalação de uma das estruturas usadas pelos mesiteros, analisarei as formas como o espaço das ruas é apropriado e as relações e os marcos que possibilitaram tal ocupação.

\section{OCUPANDO A RUA}

Ao perguntar a um mesitero como se fazia para ter uma caja na rua, ele me deu como resposta o exemplo de um companheiro que trabalhava a seu lado: "Ramón quiere poner una caja metálica. La va a poner y pueden hacerle problema, pero estamos nosotros para defenderlo. Así es que se hace". ${ }^{4}$ Alguns dias mais tarde, assim que a rua voltou a ser transitável - após os mesiteros que a ocupavam terem desarmado suas bancas - um caminhão trouxe a nova caja. Depois de muito esforço e com a colaboração de todos os companheiros de rua, a caja foi colocada no lugar onde Ramón montava diariamente sua mesita.

No meio da instalação, como que retomando a minha pergunta de alguns dias antes, o mesitero que havia começado a me explicar a forma como o espaço da rua era ocupado, agregou: "Así se hace acá, Fernando. Si viene alguien ahora se puede armar lío, pero si no, una vez que está instalada ya es difícil que le quiten". Ninguém chegou naquele momento, e a caixa ficou instalada. Dias depois, quando por ali passou o fiscal municipal que cobrava a taxa diária dos mesiteros, fez o que sempre fazia: cobrou a taxa pela ocupação do espaço e continuou seu percurso. O mesitero era o mesmo, mas agora tinha sua caja.

Ainda que decidida individualmente, a instalação se insere em um campo de relações e regras que sustentam as práticas dos mesiteros. Quem instalou a caja trabalhava naquele lugar há muito tempo. Antes de instalá-la, utilizava uma mesa desmontável na qual vendia relógios, mas também ocupava a casilla contígua a seu espaço, onde vendia CD. Como o boxe era alugado, e o dono o pedira de volta, precisava de um espaço para guardar sua mercadoria.

sobre a África do Sul, ver Nattrass (1987) e Nesvåg (2000); sobre a França, ver MacGaffey e Bazenguissa-Ganga (2000); sobre a Turquia, ver Varcin (2000); sobre a Índia, ver Jhabvala (2000), Sharma (2000) e Rajagopal (2002); sobre Barbados, ver Cutsinger (2000); sobre o México, ver Castro Nieto (1990) e Cross (1998). A formulação em termos de espacialização das trocas surgiu no Fórum de Pesquisa "Cidades e mercados: novas formas de conflito na espacialização das práticas sociais e econômicas", coordenado por Marco Antonio da Silva Mello, Luis Roberto Cardoso de Oliveira e Wilma Leitão, durante a 24. ${ }^{a}$ Reunião Brasileira de Antropologia, realizada em Olinda, entre os dias 12 e 15 de junho de 2004.

4 Ao longo do artigo, decidi manter a língua na qual as frases foram enunciadas: o espanhol. Este idioma é utilizado como segunda língua por muitos habitantes de Ciudad del Este, sendo o guarani a língua materna da maior parte dos migrantes originários do meio rural e que compõem o grupo majoritário entre os adultos da cidade. Fundada em 1957 como Puerto Presidente Stroessner, Ciudad del Este continua tendo uma marca muito visível do meio rural. Para uma análise da trajetória destes migrantes no comércio de Ciudad del Este, ver Rabossi (2004, especialmente o capítulo 5). Os nomes que aparecem no texto são fictícios. 
Aos olhos de seus companheiros e dele mesmo, a instalação da caja representava a melhoria do espaço que usava há anos para seu trabalho. Mas então, por que poderia haver problemas? Quem poderia criá-los?

Ninguém questionava que aquele lugar era dele e, em teoria, sua melhoria não era proibida. O problema, no entender de todos, era que, se aparecessem fiscais da municipalidade, podiam impedir a instalação e até mesmo tirar a caja. Mas, por quê? Várias explicações me foram dadas em resposta às minhas perguntas: seria preciso ter todos os papéis em regra, pedir autorização à prefeitura, mas as autorizações estavam suspensas. Na verdade, para os mesiteros, tais respostas jamais constituíram caminhos alternativos que pudessem ter sido tomados para a instalação da caja, evitando assim o medo dos possíveis problemas que a chegada dos fiscais da prefeitura poderia ocasionar. Em última instância, os problemas que Ramón poderia enfrentar não se deviam ao fato de ele estar agindo de forma irregular - em termos legais -, antes era a forma regular de instalar uma caja que supunha a possibilidade desses problemas.

A frase que um deles me havia dito durante a instalação, "así se hace acá", diz muito mais que a obviedade do enunciado. A frase completa citada mais acima capta os dois elementos essenciais presentes não somente na instalação da caja, mas também em muitos outros processos que operam ao redor do comércio de Ciudad del Este. Por um lado, ela sublinha a instabilidade derivada de regulamentações que não estabelecem claramente a forma certa de se fazer as coisas, gerando com isso a possibilidade de desfechos não desejados ("Si viene alguien ahora se puede armar lío..."). Por outro lado, no entanto, coloca em destaque a política de fato que se instaura em um espaço caracterizado por essa instabilidade ("una vez que está instalada, ya es difícil que le quiten").

A ideia de "política de fato" não deve ser pensada em oposição a uma "política de direito", e sim como uma forma particular de entrelaçamento entre regras e indefinições. A instalação da caja não é o primeiro ato de um roteiro que instaura um novo estado de coisas na rua, mas ela adquire sentido e legitimidade, para aqueles que estão envolvidos na ação, no conjunto de relações e regras que possibilitam que um mesitero esteja na rua. Ela não é uma ação que se realiza em um vácuo, mas uma ação decorrente das relações e das regras que a tornam possível e nelas entrelaçada. Esse entrelaçamento, para quem quer realizar uma melhoria em seu espaço de vendas, requer a necessidade de operar um ato cuja validade pode ser questionada no momento mesmo de sua realização, mas cujo resultado fica legitimado como ato consumado. Analisaremos estes elementos em detalhe adiante. 


\section{PRECARIEDADE E IRREGULARIDADE}

Pela ocupação de um lugar específico da rua, os mesiteros pagavam uma taxa diária à prefeitura. ${ }^{5} \mathrm{O}$ conceito utilizado para realizar a arrecadação desse dinheiro estava explícito no comprovante entregue a cada mesitero: "Canon diario por permiso de Ocupación Precaria de Bienes del Dominio Público Municipal". ${ }^{6}$

A taxa paga pelos mesiteros estava estabelecida nas leis municipais que determinavam a quantidade a ser cobrada e a forma como devia ser usado o espaço. Para os mesiteros, o pagamento diário da taxa legitimava de forma legal sua ocupação do espaço. Porém, em suas próprias palavras, junto com essa "legalidade" havia um défice de segurança e estabilidade. Pagar a taxa não os tirava da situação precária na qual continuavam trabalhando, tanto em relação à ocupação do lugar de trabalho quanto a outras seguranças e possibilidades.

Essa percepção não era exclusiva dos mesiteros. O reconhecimento e a regulação municipal conseguidos pelas categorias laborais emergentes em Ciudad del Este pareciam não garantir completamente a sua incorporação dentro da legalidade. No caso dos cambistas, por exemplo, essa garantia apareceu após o reconhecimento do governo central, algo que permite entrever diferentes intensidades na legitimidade das instituições governamentais. ${ }^{7}$ Falando com um cambista sobre a taxa municipal que pagavam mensalmente à municipalidade, lhe perguntei se seria possível considerar que, pelo fato de a recolherem, eram formalmente reconhecidos pelas autoridades. Ele me respondeu, referindo-se ao novo tributo nacional recém-instituído:

"Así es, reconocidos por el Estado paraguayo. Por el Estado paraguayo como trabajadores formales, legales. Es decir, a partir de que nosotros estamos pagando el tributo, justamente ya... somos legales, ¿verdad? Porque anteriormente pagábamos una tasa, acá a la municipalidad. Solo eso. Pero hoy día ya estamos pagando un tributo al Estado paraguayo. Pero ese tributo no se paga... así, por asociación, sino ya es un tributo unipersonal, como

5 O valor em 2001 era de 500 guaranis (0,12 euros). Os fiscais encarregados de cobrar percorriam a rua mesa por mesa ao longo do dia. O espaço padronizado de uma mesita - definido pela municipalidade - é de 0,80 x 1,20 metros. Como muitos mesiteros ocupam o espaço de duas ou três mesitas, pagam a taxa multiplicada pelo número correspondente delas.

6 Uma das acepções técnicas da palavra canon em espanhol é precisamente o pagamento pela utilização de uma propriedade, particularmente do Estado. Os termos da definição do valor pago pelos mesiteros seguem as diretrizes estabelecidas no artigo 123 da Ley Tributaria Municipal (Lei 620) e a Ordenanza n. ${ }^{\circ}$ 027/98 da Junta Municipal de Ciudad del Este. A tarifa estabelecida nessa lei municipal é definida como "tarifa única de quinhentos guaranis pelo espaço de uma mesita". O comprovante também tem alguns itens a serem completados: "Nome e sobrenome, Localização, Mesitero, Ambulante, Setor, Data, Assinatura e carimbo. Na prática, o recibo só é preenchido com o nome pelo qual aquele determinado mesitero é conhecido (pode ser nome, sobrenome ou apelido) e a data.

7 Cambista é a pessoa que se dedica à compra e venda (câmbio) de moedas. Em 2001, havia cerca de 600 cambistas reconhecidos pelo Banco Central paraguaio trabalhando nas ruas de Ciudad del Este. 
normalmente es... O sea, como persona física estamos tributando. No como persona jurídica. Somos un ente jurídico, es cierto, ¿verdad? Pero sin embargo pagamos unipersonalmente, así, como persona física”.

Estas percepções permitem entrever uma distribuição desigual de legitimidades, na qual o governo central aparece como "o Estado" e o governo municipal como outro ator local, com seus interesses e limitações. Não devemos imaginar, tampouco, Assunção e o governo central como um centro exemplar; eles são também recorrentemente questionados por denúncias e suspeitas que informam os olhares desde Ciudad del Este. Contudo, é certo que os regulamentos emanados de Assunção reintroduzem uma distância que permite imaginar uma lei menos sujeita às negociações particulares. ${ }^{8}$ Algo que, como veremos, não é o caso das regulamentações municipais.

Se o pagamento da taxa representava a permissão institucional para trabalhar na rua, também era um sintoma da forma que essa permissão tomava: sua precariedade. Contudo, a precariedade não derivava do sentido jurídico do termo - aquilo que se tem sem título e se deixa por tolerância ou mercê - e sim da forma como o próprio processo de consignação e ocupação realmente funcionava. De acordo com os funcionários da prefeitura, para trabalhar como mesitero, dever-se-ia iniciar um processo na prefeitura, solicitando um determinado lugar para vender: o pedido é apresentado, um fiscal verifica que o espaço solicitado esteja ocupado pela pessoa que fez o pedido e não por outra pessoa e se pode ser destinado para vendas na rua $;^{9}$ em seguida, a Junta Departamental - a câmara de vereadores - se pronuncia sobre a posse, para que esta seja legalmente reconhecida; uma vez regularizada a situação, o beneficiário paga uma taxa mensal e tem direito de usufruir desse espaço por um ano. A prática, porém, era outra.

Uma vez que alguém se estabelece em um lugar - algo que se consegue com o aval de alguma das associações que tomam conta desse espaço -, essa pessoa inicia o processo na prefeitura, obtém o comprovante que diz que o processo está em tramitação e ponto final. Se já é difícil que um fiscal peça o comprovante após a instalação, mais ainda que demande informação acerca da evolução do processo na prefeitura. Para os fiscais, se alguém está instalado em um determinado lugar é porque tem o acordo da associação e dos mesiteros que trabalham naquele espaço. Sendo assim, a tarefa do fiscal reduz-se a uma dimensão estritamente de arrecadação: se o mesitero paga a taxa correspondente, pode ficar trabalhando ali.

8 Visão que poderia ser interpretada a partir do simbolismo do poder dos centros políticos analisado por Clifford Geertz em "Centers, kings and charisma: reflections on the symbolics of power" (Geertz 1977).

9 Que se reconheça a precedência na rua como critério para outorgar ao vendedor o direito de vender naquele lugar supõe reconhecer um certo "direito adquirido" antes da sanção das regulamentações. 
Como um dos funcionários do Departamento Especial de Microcentro resumiu, a questão da ocupação da rua pelos mesiteros "Funciona un poco como derecho adquirido... Lo que nosotros hacemos es evitar peleas entre ellos por el uso del espacio, reconociendo a aquel que estaba trabajando con anterioridad". O "direito adquirido", contudo, tem suas regras e dinâmicas ligadas à prefeitura, mas não necessariamente às posturas e regulamentações. Um dos atores centrais nessa organização são as associações de mesiteros. Como veremos, elas constituem um marco organizativo fundamental para compreender a ocupação da rua e, no entanto, não são sequer mencionadas nas posturas e regulamentações municipais e, aparentemente, parecem ser completamente prescindíveis na dinâmica cotidiana. ${ }^{10}$

Uma das facetas das associações está vinculada à dinâmica contextual do dia a dia, atendendo problemas pontuais que podem emergir na instalação de uma caja, por exemplo. Outro aspecto menos visível, porém crucial para entendê-las, é que elas foram - e ainda são - os meios organizativos privilegiados pela prefeitura para o ordenamento da ocupação do espaço. Neste sentido, a associação tem uma importância fundamental no momento em que alguém tenta conseguir um lugar específico para vender na rua.

Ainda que em outras épocas as associações controlassem firmemente o espaço, não era assim que se passava durante meu trabalho de campo. A desaceleração do movimento comercial relaxou a pressão sobre a rua, e o lugar que as associações detinham no controle do espaço não aparecia no cotidiano. Contudo, falando sobre os momentos em que outros haviam começado a trabalhar e, especialmente, com aqueles que não conseguiram um lugar, a importância das associações se revelava de forma marcante. A essa história me referirei a seguir.

\section{PROLIFERAÇÃO: REPRESSÃO, MONOPÓLIO E FRAGMENTAÇÃO}

Em 1968, alguns anos depois da inauguração da Ponte da Amizade, que liga o Brasil ao Paraguai, chegaram os primeiros vendedores de rua vindos de Assunção à então chamada Puerto Presidente Stroessner. Após alguns anos de repressão ao comércio ambulante, as autoridades da cidade começaram a aceitar a presença do mesmo e, em 1971, foram estabelecidos critérios para se trabalhar na rua de forma regulada. A primeira questão era organizar-se. Tal como fora descrito por um dos primeiros dirigentes mesiteros,

10 Eram várias as associações de mesiteros que funcionavam durante meu trabalho de campo e entre elas estavam: a Asociación de Mesiteros de la Avenida San Blas; o Sindicato de Vendedores Feriantes de Ciudad del Este; a Asociación de Comerciantes de Ciudad del Este - Lenteros Unidos; o Sindicato de Trabajadores Vendedores de Artículos Electrónicos, Musicales, Culturales, Revistas y Afines en la Vía Pública del Alto Paraná; a Asociación de Trabajadores Fronterizos del Este; a Asociación de Trabajadores de Golosinas; a Asociación de Vendedores de Cosméticos; a Asociación de Vendedores de Artículos Típicos; a Asociación de Vendedores de Mercería; o Sindicato de Mesiteros Unidos. 
"En aquel tiempo, [los de] la autoridad administrativa nos dijeron, 'Bueno, ganaron ustedes la batalla pero... no la guerra, pero organícense, pónganse, identifíquense, fíjense que esta es la ciudad que lleva el nombre del presidente, Stroessner, el fue el fundador, y acá las personas tienen que estar bien identificadas.' Nosotros como ciudadanos... listo, nos identificamos, nosotros queríamos trabajar, trabajábamos, nos convenía”.

Em agosto de 1972 formou-se a Asociación de Lenteros Unidos, nucleando esse primeiro grupo de ambulantes vindos principalmente de Assunção. ${ }^{11}$ O termo lenteros deriva de um dos produtos que vendiam naquela época: óculos de sol, em espanhol também chamados de lentes oscuros. A outra associação formada por aqueles que começaram a vender nas ruas foi a Asociación de Vendedores de Artículos Típicos, que nucleava as pessoas que vendiam produtos artesanais do Paraguai que, por derivação, passaram a ser conhecidos como típicos.

Para poder vender na rua, naquela ocasião, era preciso estar vinculado a alguma das associações, as quais tinham um limite fixo estabelecido pelas autoridades: 54 membros em cada uma delas. Lenteros e típicos foram os primeiros vendedores de rua reconhecidos a trabalhar em Puerto Presidente Stroessner. Seu reconhecimento, além de legitimar as vendas nas ruas, outorgou o monopólio para fazê-lo às associações recém-fundadas. No entanto, se a possibilidade de se estabelecer em um determinado lugar da rua ficou restrita a esses 108 vendedores, nada foi estabelecido sobre a possibilidade de se ter empregados. Assim, se a rua ficou fechada para novos vendedores habilitados, o comércio mesitero expandiu-se pela mão dos empregados que trabalhavam para aqueles já habilitados. Os secretarios - tal como eram chamados - passaram a ser uma figura recorrente do comércio de rua. ${ }^{12}$

As estruturas organizativas criadas para representar os vendedores foram uma parte constitutiva da regulação da rua. As associações ou sindicatos - tal como também eram chamados - controlavam o uso do espaço, além de outras

11 Dos 54 membros que faziam parte da associação quando ela foi fundada, 33 provinham de Assunção e o restante de outras cidades do interior, tais como Coronel Oviedo, Villa Rica, Concepción e Juan León Mallorquín. No ano de 2001, a Asociación de Comerciantes de Ciudad del Este - Lenteros Unidos (este era seu nome naquele momento) contava com 87 membros, distribuídos em uma área construída na avenida central (36) e nas ruas (51).

12 A figura do secretario continua a ser central na dinâmica da rua e refere-se àquele que trabalha com as mercadorias de outra pessoa nas ruas de Ciudad del Este, distinguindo se a pessoa é patrão de si mesmo ou se trabalha para outro. A definição mais comum que escutei de secretario é "aquela pessoa que te ajuda em tua mesa". As atividades enumeradas para descrevê-lo vão desde cuidar da mercadoria, ajudar a desenrolá-la e guardá-la, oferecê-la e vendê-la, preparar o tereré - infusão gelada de erva mate tomada como chimarrão - ou servi-lo, conseguir troco, pagar contas ou fazer trâmites. Che patrón é a contrapartida do secretario: o dono da mercadoria para quem se trabalha. A fórmula che patrón revela a estreita interação entre guarani (che, adjetivo possessivo da primeira pessoa do singular) e espanhol (patrón). 
questões igualmente importantes, como, por exemplo, a margem de lucro mínima sobre os produtos, ${ }^{13}$ ou ainda, a distinção de mercadorias que os sócios de cada associação podiam vender. Tal como os nomes sugerem, cada associação comercializava produtos diferentes. Embora essa distinção pudesse ser traçada através da origem dos mesmos (típicos = paraguaios; lenteros = importados), ela se estabeleceu a partir da distinção entre produtos artesanais e industrializados. Um exemplo lembrado por vários mesiteros para assinalar o quão rígida era essa divisão era o caso das guampas e das bombas. A guampa é uma vasilha (copo) feito de chifre de boi, utilizada junto à bomba para se tomar tereré, o chimarrão gelado muito comum na região. As bombas "eram" dos lenteros e as guampas dos típicos. Os membros de uma associação não podiam vender aquilo que os membros da outra vendiam, algo que, neste caso - dois artigos que só funcionam combinados - sublinhava a arbitrariedade da divisão.

Falando com os mesiteros em 2001, mesmo que essa divisão fosse lembrada como algo arbitrário, era recordada por muitos com a saudade de um tempo de ordem que mais tarde acabaria. Para outros, contudo, era o símbolo da arbitrariedade dos tempos de Stroessner, pois essa divisão tinha sido estabelecida pela Confederación Paraguaya de Trabajadores e representava um limite às possibilidades do comércio. ${ }^{14}$

Anos mais tarde, em 1978, o prefeito de Puerto Presidente Stroessner propôs aos lenteros e aos típicos que saíssem da rua e ocupassem parte dos canteiros centrais da Rodovia Internacional, a artéria principal que, saindo da Ponte da Amizade, atravessa a cidade e segue rumo ao centro do Paraguai. Lenteros e típicos ocuparam espaços diferentes, onde construíram seus locais de vendas.

A década de 70 foi o período de legitimação das vendas na rua e de ocupação de alguns espaços que terminaram com o estabelecimento dos vendedores nos locais construídos no passeio central. Quando os primeiros vendedores começaram a trabalhar, as ruas eram um espaço a ser conquistado para as vendas. $\mathrm{O}$ processo que vai da repressão ao acordo com as autoridades para se poder trabalhar de forma regulada poderia ser descrito como um processo de legitimação e de incorporação. Legitimação de uma determinada atividade

13 Não era permitido vender por menos de $40 \%$ de lucro sobre o valor de um produto. Isto é, um produto cujo custo era 10, não podia ser vendido por menos de 14 . Como o descreveu um mesitero, "eso era una ley en aquel entonces". Claro que o limite estabelecia a margem inferior do lucro (garantia um chão abaixo do qual não se podia competir), mas não seu teto: acima do limite não existia restrição e dependia do que cada vendedor conseguisse negociar com seus clientes.

14 A Confederación Paraguaya de Trabajadores (CPT) foi fundada em 1951. Após uma greve geral em 1958, sofreu intervenção do governo de Stroessner, e sua direção passou a um oficial da polícia. A partir de então, ficou sob controle do governo e de seu partido. Em 1985, foi desligada da Organização Internacional do Trabalho (OIT), após uma delegação da OIT corroborar que os princípios básicos para integrá-la - assegurar que fosse uma instituição democrática e independente do governo - não eram respeitados. De acordo com os mesiteros que trabalhavam naquela época, foi a CPT que estabeleceu a distinção por produto. 
(vendas ambulantes), realizada num determinado espaço (a rua). Incorporação tanto aos marcos institucionais, nesta época controlados pelo governo (as associações em relação à central dos trabalhadores), quanto à dinâmica delineada pelas instituições (os vendedores em relação às associações reconhecidas pela administração da cidade).

A formação e consolidação de estruturas organizativas de vendedores foi um dos meios fundamentais nesse processo e, por sua vez, um dos resultados do mesmo. Isso implicou a constituição de uma nova institucionalidade, produto de acordos entre autoridades e vendedores. Estes acordos significaram a consolidação de estruturas organizativas que passaram a regular o espaço da rua, as quais, por sua vez, passaram a desfrutar de seu monopólio.

O alcance das organizações transcende essa dimensão política - particularmente no caso da Lenteros Unidos - e se inscreve na própria constituição da cidade através de uma série de ações (melhorias das ruas, clube, atividades sociais) que estão impressas na memória de muitos de seus habitantes.

As mudanças que ocorrem na cidade, no comércio e nas estruturas de vendas, na década de 70 têm de ser situadas no marco daquilo que transformaria de forma radical a região: a construção da usina hidrelétrica de Itaipu. Muitas das histórias que conheci nas ruas e nas lojas de Ciudad del Este começavam com Itaipu. Como pude verificar durante meu trabalho de campo, essa experiência fora vivida de forma direta por aqueles de 40 anos ou mais, ou, entre os mais jovens, a partir de seus pais e familiares, e não se restringia aos paraguaios, sendo também recorrente entre empregados, comerciantes e brasileiros dedicados à passagem de mercadorias - os denominados laranjas. Atraídos por Itaipu, nem todos conseguiram trabalhar na barragem. Aqueles que o fizeram tampouco tiveram uma trajetória homogênea: alguns trabalharam um par de anos, outros, por quase uma década. ${ }^{15}$ As histórias de muitos mesiteros começam na busca por trabalho em Itaipu. Para alguns, vender no centro apresentou-se como uma alternativa enquanto se esperava pela resposta da hidrelétrica. Para os que não conseguiram trabalho, era uma alternativa antes de retornarem a seus lugares de origem.

15 Itaipu foi um ponto de inflexão no desenvolvimento de Ciudad Presidente Stroessner e Foz do Iguaçu. Sua construção começou em 1974 e, em maio de 1984, foi inaugurada a primeira unidade geradora de energia. Segundo cifras da Itaipu Binacional - ente binacional encarregado da construção e do gerenciamento da hidrelétrica -, 1978 foi o ano em que houve o maior número de pessoas empregadas: 31.318 trabalhadores. De acordo com ex-trabalhadores e funcionários que continuavam em Itaipu em 2001, do total de trabalhadores, aproximadamente um terço era paraguaio e dois terços eram brasileiros. As cifras oficiais de distribuição de mão de obra por nacionalidade (43\% paraguaios e 57\% brasileiros) também têm sido questionadas por outros autores (Baer e Birch 1984: 789 e 798). Para um quadro detalhado dos empregados de Itaipu de 1974 a 1984, ver Sotuyo (1998: 25). Para uma visão abrangente da construção da hidrelétrica e do impacto na região, ver Souza (2008). 
Se a possibilidade de estabelecer-se como vendedor reconhecido era limitada pelo número estipulado aos típicos e lenteros, todos estes novos vendedores incorporaram-se como ambulantes (como tinham feito os primeiros) ou como secretarios de algum mesitero já instalado. Assim, ainda no momento em que a regulação foi mais eficaz, as ruas continuaram se ampliando como espaço de vendas.

Se a construção de Itaipu constituiu um ponto de inflexão no desenvolvimento de Ciudad Presidente Stroessner, a mesma insere-se num movimento mais amplo que teve início com a própria fundação da cidade e a expansão da fronteira agrícola no leste do Paraguai. Em outro lugar, analisei esses processos em detalhe (Rabossi 2008: 190 e segs.). O que me interessa destacar aqui é que a conjunção de todos esses movimentos transformou, em menos de 50 anos, uma região escassamente povoada na segunda cidade de Paraguai e no departamento de maior produção agrícola do país.

À medida que as fases de construção de Itaipu que demandavam mais mão de obra iam sendo completadas - entre 1982 e 1984 - grande parte dos trabalhadores ia sendo dispensada. Muitos dos que haviam começado a trabalhar na barragem enfrentaram a situação daqueles que não tinham conseguido ingressar: inserir-se em alguma atividade em Puerto Presidente Stroessner ou voltar para "sus valles".

Nesta ocasião, a rua já tinha se transformado num espaço de vendas, habitada não somente pelos 108 vendedores habilitados, mas também por seus secretarios e ambulantes que vendiam por conta própria. Ser mesitero deixou de ser uma atividade concebível para aqueles que chegavam à cidade, transformando-se numa atividade desejável. A exemplo dos progressos materiais de típicos e lenteros, que após 1978 haviam conseguido instalar-se em locais fixos construídos nos passeios centrais, as vendas na rua se tornaram uma atividade promissora. A possibilidade desse tipo de venda não depende, contudo, tão somente de poder concebê-lo, nem de ver que outros também o fazem e de receber sua ajuda para se incorporar nessa dinâmica. Também, depende das condições de uso e regulação do espaço e das vendas que, como fomos vendo, estabelecem limites importantes. No entanto, esses arranjos não foram permanentes e mudaram com as transformações que alteraram a dinâmica da cidade.

Nos anos 80, surgiram novas associações que conseguiram ocupar outros espaços e colocar seus associados na rua. As vendas nesta última, que já tinham deixado de ser exclusivamente feitas por típicos e lenteros, eram também reguladas por outras organizações, como a Asociación de Vendedores de Cosméticos, a Asociación de Trabajadores de Golosinas, o Sindicato de Trabajadores Vendedores de Artículos Electrónicos, Musicales, Culturales, Revistas y Afines en la Vía Pública del Alto Paraná, nomes que permitem igualmente entrever a dissolução das categorias que haviam organizado o mundo dicotômico de típicos e lenteros (paraguaio e artesanal vs. importado e industrializado). 
Assim como a possibilidade de se estabelecer legalmente na rua nos inícios dos anos 70 foi conseguida a partir de um acordo com as autoridades, uma década mais tarde, a ampliação deste acesso foi conseguida a partir de novos acordos. Entretanto, do mesmo modo que a cidade tinha se transformado profundamente nessa década, também o tinham feito os loci de poder, multiplicando-se os canais e as figuras em condições de garantir a possibilidade de se vender na rua. ${ }^{16}$

Se as novas associações tentaram colocar limites ao acesso à via pública, o próprio processo de proliferação que as havia tornado possíveis impediu que tivessem o caráter fechado que lenteros e típicos gozaram por certo tempo. As condições monopolistas de usufruto da rua já não conseguiram ser reproduzidas da forma feita até então, algo que permite vislumbrar a profundidade das mudanças em curso.

Um processo de multiplicações variadas estava mudando o centro da cidade: multiplicação de construções, de lojas e de comerciantes; de associações de vendedores que abriram novos espaços na rua; de instituições que se envolveram no seu controle e em sua regulação; de áreas que começaram a entrar em tensão pelo seu uso - ou restrição dele - como espaço de vendas; de guardas privados e de funcionários interessados em tirar proveito desse movimento.

É nesse espaço de multiplicações que começa a tomar forma aquilo que se constituirá na característica do desenvolvimento do microcentro: a permanente articulação entre uma dimensão micropolítica do espaço (a negociação com o guarda que controla a entrada de uma galeria, por exemplo), a política da rua (os sindicatos e as instituições que regulam e controlam seu funcionamento) e a política sindical e partidária em nível regional e nacional (expressas localmente através de funcionários e políticos). Essa articulação não se restringe ao caso dos mesiteros, antes atravessando a dinâmica de todas as atividades do centro da cidade.

\section{DISJUNÇÕES DA RUA}

A possibilidade individual de ocupação de um espaço para vender era mediada pelo pertencimento a uma associação de mesiteros e, tal como vimos até agora, constituía a chave de acesso à rua. Essa era, ainda durante meu trabalho de campo, a principal razão de ser das associações. Por exemplo, explicando o caráter do Sindicato de Trabajadores Vendedores de Artículos Electrónicos, Musicales, Culturales, Revistas y Afines en la Vía Pública del Alto Paraná, seu presidente assim o caracterizava:

16 Ao prefeito da cidade e ao governador do departamento somam-se outras figuras, como o presidente da câmara de vereadores, o presidente da seção do Partido Colorado - o partido de governo - e os diversos representantes do governo nacional na guarnição militar, na polícia, no departamento de trabalho, na aduana, na oficina de migrações, entre outros. 
"El sindicato por lo menos no, no, no está trabajando como un sindicato, porque solamente nosotros sindicalizamos para trabajar en la calle. No tenemos ninguna cooperativa, no cooperamos juntos, solamente trabaja uno para cada uno en la calle y tenemos un local, pero... ese local, solamente es para hacer reuniones con los muchachos".

Falando sobre as outras associações, outro dirigente me explicava:

“Todas son asociaciones, ¿̇me entendés? Todo se fundó acá en las calles porque necesita de la asociación, entonces se fundó la asociación, entonces todas las asociaciones están reconocidas por el Ministerio de Justicia y Trabajo. Legalmente constituido, cada dos años hay elecciones para elegir nuevos dirigentes, para elegir nuevo presidente..."

Este "efeito associativo" - a formação de associações no processo de regulação de uma categoria profissional - está presente em todos os processos experimentados pelas categorias laborais emergentes em Ciudad del Este, sejam cambistas, mesiteros, kombistas, mototaxistas, paseros ou ambulantes. A aceitação e a regulação de cada categoria implicaram a constituição de associações que passaram a representá-la frente às autoridades, desempenhando um papel fundamental na regulamentação do trabalho e, posteriormente, na implementação dessas regras. ${ }^{17}$ Dada a centralidade do espaço na realização das vendas, no caso dos mesiteros, as associações foram encarregadas da distribuição e do reconhecimento de um lugar para seus associados.

As diferenças entre os procedimentos descritos pelos fiscais municipais e pelos mesiteros, mencionados no início do artigo, começam a adquirir sentido à luz de uma série de contradições emergentes do processo de regulamentação do trabalho nas ruas. A primeira contradição é entre indivíduo e associado: o sujeito elegível das posturas municipais é um indivíduo particular. Não há menção às associações, nem espaço para elas, nos procedimentos descritos nessas posturas. Contudo, são as associações que têm, junto da prefeitura, o controle do espaço.

Esta contradição entre o indivíduo das posturas e o coletivo das práticas de concessão e controle do espaço remete a outra contradição, neste caso, de ordem temporal. $\mathrm{O}$ mundo das posturas e das regulamentações constitui-se como ato de fundação que inaugura o reconhecimento e a implementação de uma nova forma de trabalho. Com a sanção dessa postura municipal, em teoria, o tempo começaria a ser contado a partir de sua implementação.

17 Falo de aceitação e não de reconhecimento porque se trata do ato de consentir uma prática até então ignorada ou considerada fora da lei. $\mathrm{O}$ reconhecimento não necessariamente implica consentimento àquilo que é reconhecido. Por exemplo, as políticas de repressão ao comércio de rua, implementadas em muitas cidades do mundo, partem do reconhecimento dos vendedores como pessoas que atuam fora da lei ou contra ela. 
Sabemos, porém, que o reconhecimento do trabalho na rua é anterior à sua regulamentação, chegando-se ao momento da sanção da postura através de uma série de processos que passaram da repressão à aceitação e da associação à regulação; algo que poderíamos resumir dizendo que o tempo "fundacional" da postura está imerso no processo que levou à sua sanção. Se esta observação é válida para qualquer acordo ou regulamentação, especificamente neste caso, as formas de organização e de regulação anteriormente condensadas e que formam parte da regulação efetiva da rua têm como consequência a impossibilidade de se aplicar algumas das regras estabelecidas nas posturas municipais. No momento de implementação da postura, o mundo já estava constituído e é na aceitação dessa constituição que assentam as bases para a reprodução de um sistema que não corresponde àquilo nelas estabelecido.

Estas duas contradições - indivíduo/associado e tempo fundacional/processo histórico - permitem entender a disjunção entre o marco legal e as práticas que caracterizam o trabalho nas ruas de Ciudad del Este. As posturas municipais são o marco de legitimação do trabalho, mas não o marco de regulamentação da atividade. Isto cria a situação antes mencionada a propósito da instalação da caja: dado que o que se faz não está de acordo com o estabelecido nas posturas, a possibilidade de se "ter problemas" sempre existe. No caso dos mesiteros e de muitos daqueles que participam do comércio de Ciudad del Este, a instabilidade percebida a respeito das condições de trabalho deriva da operação de distintos marcos regulatórios: alguns derivados dos processos que levaram à organização do trabalho, outros contemplados nas posturas, outros inclusive - emergentes de consensos particulares entre alguns dos interessados. Os aspectos indefinidos ou contraditórios entre esses distintos marcos regulatórios são contrabalançados a partir de uma política de fato que reproduz, por sua vez, as condições de precariedade.

Tanto no tempo de ocupação dos espaços como nos regimes de apropriação dos mesmos, essa dinâmica aparece de forma exemplar. De acordo com as posturas municipais, a habilitação para trabalhar em um dado lugar é outorgada pelo período de um ano, ao término do qual o espaço deve ser reintegrado na prefeitura, independentemente do fato de ter sido melhorado pelo vendedor ou não. Por outro lado, a habilitação é para uso pessoal do solicitante, não pode ser transferida por venda ou aluguel. Porém, tal como a casilla alugada por Ramón demonstra, a prática de aluguel é bastante comum, assim como as de venda de espaços - práticas que são possíveis porque os espaços são ocupados de forma permanente. ${ }^{18}$

18 No período de campo, não soube de nenhum caso de venda do espaço de uma mesita, e sim de cajas e casillas. Aqui, outra vez, as particularidades de cada lugar alteram as possibilidades e as condições para alugá-las ou vendê-las. Por exemplo, os donos de um negócio que estava sendo aberto em 2001, na Av. Monseñor Rodríguez, propuseram comprar a caja do mesitero localizado em frente deles. Queriam comprá-la para retirá-la e, assim, ganhar maior visibilidade na rua. O mesitero [continua] 
Assim, aquilo que devia ser temporário se torna permanente, e essa permanência, por sua vez, reafirma as condições precárias de apropriação. Como os procedimentos estabelecidos nas posturas não são aplicados, a apropriação não tem seu limite temporal definido por elas. Isto permite uma ocupação de longa duração que torna plenamente concebível, por exemplo, instalar uma caja no espaço no qual se trabalhou por anos, tal como vimos no exemplo apresentado. Contudo, essa mesma duração significa igualmente a emergência de uma situação que não se ajusta ao estabelecido nas posturas, transformando a ocupação em uma situação de permanente exceção. Neste sentido, precariedade e permanência se retroalimentam nas condições de apropriação da rua no centro de Ciudad del Este.

O espaço ocupado pelos mesiteros pode ser dotado de estruturas permanentes, a posse do mesmo pode durar anos e, inclusive, o lugar e a infraestrutura podem ser vendidos. No entanto, as condições de apropriação desse espaço não alteram a condição de precariedade. Se as condições atuais de posse concedem algumas garantias em termos de apropriação do espaço (temporalmente falando e em relação às condições em que essa apropriação pode ser efetivada), tais condições reafirmam a insegurança permanente de sua posse ao reproduzirem as condições precárias de ocupação.

Tal como ocorre com a instalação, o aluguel e a venda de cajas e casillas também nos colocam diante de um sistema que, ainda que conte com algum apoio na legalidade estabelecida pelas posturas municipais, implica ações contraditórias em relação a essa mesma legalidade. De fato, o sistema descansa em uma série de arranjos que foram se sedimentando paralelamente à dinâmica comercial da cidade e que, na prática concreta, têm sua legitimidade derivada de uma ordem relacional cuja validade se apoia no reconhecimento dos atores envolvidos e cuja garantia se assenta nas associações de mesiteros, nos vizinhos e companheiros de trabalho e nos fiscais que cobram diariamente a taxa.

A quantidade de vendedores que trabalha nas ruas é enorme, e seu grau de apropriação sobre o espaço, bem expressivo, se levarmos em conta o tipo de estrutura permanente instalada e os regimes de venda e aluguel das mesmas e dos lugares ocupados pelos mesiteros. Existe, contudo, um défice de estabilidade derivado das condições em que os marcos regulatórios são estabelecidos e que amplificam, paradoxalmente, as condições de precariedade, bem como o grau de apropriação da rua. Se a precariedade, em seu sentido genérico de pouca estabilidade, é característica da forma como a rua é ocupada, então a política de fato, mencionada a propósito da instalação da caja, é uma necessidade para

pediu 4000 dólares. O comerciante ofereceu 3000. O mesitero pediu 3800 e fecharam o acordo por 3500 dólares. Tão logo comprou a caja, o comerciante a retirou e instalou barras de metal para evitar que alguém ali pudesse se instalar novamente. O mesitero, por sua vez, comprou outra caja na mesma calçada onde havia trabalhado até então e por ela pagou 700 dólares. 
se poder atuar. Como em uma estrutura dinâmica que só existe em movimento, o trabalho dos mesiteros - a ocupação do espaço ou as melhorias do mesmo, por exemplo - é possível a partir das ações que atualizam as possibilidades de se fazer em um mundo que o permite, mas que o mantém na sombra daquilo que pode vir a ser excluído.

Se as contradições até aqui apresentadas entre o tempo das regulamentações e os sujeitos nelas elegíveis permitiram compreender a disjunção entre os marcos legais e as práticas reais que acontecem na rua, a articulação entre a micropolítica do espaço, a política da rua e a política regional e nacional, mencionada na descrição histórica do processo de ocupação da mesma, é o que permite entender as formas pelas quais ela foi ocupada de forma concreta. Os marcos legais, antes de serem códigos para a ação, operam como fundamentos de legitimidade e provedores de diretrizes da forma como essas múltiplas dimensões políticas operam na prática. Neste sentido, permitem entender a convivência de arranjos legais para a regularização da situação dos mesiteros com a reprodução de outros que os contradizem, mas que garantem uma regulação negociada a partir destas articulações políticas.

\section{ABRINDO ALGUMAS DISCUSSÕES, À GUISA DE CONCLUSÃO}

A Tríplice Fronteira adquiriu um lugar de destaque nos meios de comunicação internacionais e nas agendas governamentais de segurança diante das denúncias sobre tráficos de drogas e armas e lavagens de dinheiro e de bens roubados, assim como pela suposta presença de terroristas islâmicos e máfias transnacionais, além do contrabando e da comercialização de produtos falsificados. A ausência de lei, derivada da ausência de controle governamental, da perda de controle estatal, da corrupção e da falta de recursos, é o diagnóstico recorrente para dar conta do que acontece naquele espaço. Vejamos, como exemplo, algumas descrições e explicações para os problemas presentes na região:

“... the lack of government control in the area, the lack of resources to combat criminal activities and rampant corruption among bureaucrats and law enforcement officials" (Madani 2002).

"[L]a pérdida de control estatal de territorio a manos de organizaciones criminales y redes terroristas es clara en el caso de Ciudad del Este, al punto que un editorial periodístico paraguayo habla de 'santuarios' y 'territorios liberados’ anidados en suelo nacional” (Bartolomé 2002: 73). ${ }^{19}$

19 Essa caracterização corresponde de fato a uma das definições do conceito de "área cinza", utilizado na década de 90 nos estudos de segurança internacional e sugerido pelo autor para descrever a região. As definições de "área cinza" apontadas por Bartolomé são as seguintes: áreas onde o controle do território está nas mãos de organizações metade criminais, metade políticas; áreas onde as [continua] 
"In Ciudad del Este, the absence of government control allows smugglers and money launderers to leverage disparity in the levels of law enforcement, import regulations, exchange rates, and tax rates between Paraguay and its neighbors" (Mendel 2002: 53).

Os diagnósticos sobre a Tríplice Fronteira apresentam um espaço definido pela ilegalidade. Então, já que o problema é a ausência da lei, a solução é torná-la presente: levá-la, efetivá-la, reforçá-la.

Contudo, para quem faz pesquisa na região, os problemas começam justamente aí, porque o postulado da ausência de legalidade está em contradição com a presença multiplicada de instituições e funcionários encarregados de efetivá-la. Por exemplo, em 2001, eram 17 instituições paraguaias localizadas na saída da Ponte da Amizade. A Delegacia da Receita Federal de Foz do Iguaçu era e continua sendo uma das mais importantes do Brasil. Ao se entrar na Argentina pela Ponte Tancredo Neves, o controle é um dos mais rigorosos do país. Juntamente com as instituições e funcionários que tomam conta das passagens, também estão presentes nas três cidades as forças armadas de cada país, suas várias polícias, um comando tripartido de segurança, assim como agências de informações estrangeiras e locais. Inclusive, em termos de segurança, a "colaboração" internacional não é nova, como demonstram as operações da agência norte-americana antidrogas e de sua central de informações, que se tornaram públicas e que remontam à década de 80 .

É verdade que a presença estatal não é garantia de cumprimento da lei. Afinal, a corrupção também é assinalada como um dos ingredientes essenciais do quadro da Tríplice Fronteira. Contudo, se a falta de garantias estatais é o que caracteriza a região, não deixa de ser surpreendente o incentivo do governo norte-americano a empresas para trabalhar em Ciudad del Este, inclusive no final de 2001, após funcionários do mesmo governo terem recorrentemente denunciado aquele espaço como a sede do terrorismo internacional na América Latina. ${ }^{20}$ Se é tão claramente o lugar por onde entra grande parte do contrabando no Brasil e o lugar de saída dos automóveis roubados nesse país, como explicar os esforços do governo brasileiro para concretizar a projetada segunda ponte sobre o rio Paraná, paralela à Ponte da Amizade?

O que quero assinalar é a inadequação entre o retrato da insegurança e da ilegalidade e aquilo que se faz e incentiva naquele espaço fronteiriço. Com isso,

fronteiras entre interno e externo, em termos de segurança, dissolveram-se; áreas de "não direito", nas quais se refugiam e operam grupos criminais e terroristas (Bartolomé 2002).

20 O incentivo aparece no guia comercial do Paraguai, do Departamento de Comércio do Governo dos Estados Unidos (USATRADE 2001). Há um guia comercial para cada país, elaborado pelo pessoal de cada embaixada, de acordo com os delineamentos estabelecidos pelo U. S. Commercial Service, agência do Departamento de Comércio. Nos guias, analisa-se a situação econômica de cada país e a situação política em função dos efeitos que possam ter sobre os negócios de empresas estadunidenses. 
não estou dizendo que o que aparece como objeto das denúncias seja invenção dos meios de comunicação ou de funcionários interessados. O ponto que quero destacar é que as denúncias que informam o retrato da Tríplice Fronteira operam em função de modelos de ordem e de lei que talvez não sirvam para pensar o funcionamento efetivo da lei nem as atividades que se desenvolvem naquele espaço. As inconsistências e contradições entre as agendas políticas e as agendas econômicas que emergem desses retratos derivam de modelos contraditórios sobre o que é mercado e Estado, legalidade e desenvolvimento econômico. ${ }^{21}$

Se a ilegalidade é utilizada como critério de definição da realidade da fronteira, as perguntas que esse diagnóstico suscita apontam para a compreensão das condições que tornam tais práticas possíveis. O legal é o roteiro de como as coisas deveriam ser e, além de definir o normal, ilumina aquilo que devemos compreender: o ilegal (o anormal) e suas condições de possibilidade e de funcionamento. O que se torna invisível desta perspectiva é a própria lei e o funcionamento de fato do Estado, e aqui é que entra a escolha do material dos mesiteros para o presente dossiê. ${ }^{22} \mathrm{~A}$ entrada na dinâmica fronteiriça a partir do trabalho destes últimos nos permite enxergar um mundo em que as regulamentações se tornam um elemento-chave na forma de gerenciar aquilo que se encontra à margem da lei, mas que, ao invés de incorporá-lo no universo da legalidade, o mantém no limite, a partir da reprodução da precariedade.

A pergunta que se nos coloca imediatamente é sobre o alcance dos elementos até agora apresentados. Em outras palavras, o material apresentado não será resultado das condições singulares nas quais os mesiteros realizam seu trabalho? Ao analisar todas as categorias laborais atuantes no comércio de Ciudad del Este e que aos poucos foram sendo regularizadas, encontramos o mesmo padrão verificado para os vendedores de rua. Seja começando uma nova atividade (como no caso dos cambistas, dos paseros e dos mesiteros) ou competindo com formas já estabelecidas (caso dos kombistas e dos mototaxistas em concorrência com os taxistas), todas estas categorias passaram por um começo marcado pela repressão ou pelo conflito com outros trabalhadores, que derivou em um processo de negociação para a regularização. ${ }^{23}$ Formadas neste

21 Em outros trabalhos, analisei questões que se inscrevem de forma direta nos problemas registrados nas agendas de segurança, mas abordados a partir de outras perspectivas. Sobre o comércio (contrabando), ver Rabossi (2004: 236 e segs.). Sobre migrantes libaneses (terroristas), ver Rabossi (2007). Vários trabalhos têm desconstruído a imagem da Tríplice Fronteira e analisado a sua reconfiguração como problema de segurança internacional, como, por exemplo, Rabossi (2004: 21 e segs., 2010a, 2010b), Montenegro e Béliveau (2006), Karam (2010) e Amaral (2010).

22 O argumento sobre aquilo que se torna invisível no caso da análise de ilegalidades deriva do trabalho de Nicholas de Genova sobre a produção da "ilegalidade migrante", no caso dos migrantes mexicanos nos Estados Unidos (De Genova 2002).

23 No Paraguai, pasero (em espanhol) é a pessoa que passa mercadoria através do limite internacional para vender do outro lado da fronteira. Naquela aqui analisada, os paseros só trabalham no fluxo de mercadorias de Foz do Iguaçu a Cuidad del Este, pois o fluxo contrário é controlado por [continua] 
processo, as associações e as regulamentações passaram a legitimar e ordenar as práticas permitidas. Em todos os casos, a possibilidade de trabalhar passou a estar mediada pelo pertencimento a uma associação que terminou monopolizando essa atividade. Enquanto o número de associados e de associações se manteve sob controle, as diferenças entre a regulamentação escrita e as formas práticas de regulamentação não se tornaram significativas, assemelhando-se a categorias laborais estáveis nestes períodos. Nos casos em que as associações e os associados se multiplicaram por fora dos canais anteriormente acordados, essas diferenças passaram a adquirir um novo sentido, desvendando as distâncias entre o combinado e o permitido e revelando a instabilidade sentida por muitos dos que participavam destas atividades.

O surgimento e a consolidação de todas essas práticas estão entrelaçados com as dinâmicas legais e associativas que, a partir da forma como operam, funcionam como uma multiplicação regular de irregularidades, que se revelam como tal somente quando o acordo que estabilizava o reconhecimento e a regulação de determinada atividade se vê questionado por novas pessoas que também querem trabalhar na mesma categoria. ${ }^{24} \mathrm{~A}$ produção de atores coletivos no processo de regularização de uma atividade perante o Estado - o que anteriormente chamei de "efeito associativo" - aparece também nas análises sobre vendedores de rua em outras partes do mundo. No caso da Cidade do México, estudado por John Cross, as organizações são o resultado das pressões administrativas que exigem aos vendedores estarem afiliados a uma associação reconhecida para poderem ocupar um determinado lugar. ${ }^{25}$

O caso analisado por Cross (1998) permite extrair alguns dados que transcendem o local e que apresentam elementos estruturais, como o tipo de integração estatal e a prática política de grupos não representados nos

brasileiros (sacoleiros e laranjas). Os kombistas são aqueles que dirigem uma kombi ou van e constituem o denominado "transporte alternativo". Em 2001, havia mais de 600 kombistas transportando compradores que retornavam ao Brasil com suas mercadorias. Os mototaxistas são aqueles que realizam um serviço de táxi em motocicleta; a denominação é utilizada em ambos os lados da fronteira e em 2001 havia 150 mototaxistas trabalhando em diversas associações em Ciudad del Este. Segundo estimativas de mototaxistas, havia mais de 1100 mototaxistas em Foz do Iguaçu trabalhando no transporte de mercadorias e pessoas.

24 Em Cuidad del Este, a multiplicação regular de irregularidades não é uma dinâmica exclusiva das novas atividades, mas também daquelas já estabelecidas. Os comércios constituem o caso mais evidente, muitos dos quais funcionando a partir da utilização sistemática de mão de obra brasileira indocumentada e do pagamento irregular de impostos.

25 O trabalho de John Cross questiona uma visão corrente nas análises do comércio de rua - e da denominada "economia informal" em geral - que explica seu surgimento e desenvolvimento exclusivamente a partir de fatores econômicos. Questionando esse pressuposto, Cross analisa o comércio de rua histórica e etnograficamente, considerando os vendedores de rua como atores políticos e abordando as suas formas de articulação e resistência diante do Estado. Se, por alguns momentos, as associações surgem como expressão dos interesses dos vendedores em contextos repressivos, na análise mais ampla e de longa duração, o desenvolvimento associativo dos vendedores é resultado da interação com o Estado (Cross 1998: 147 e cap. 5). 
enquadramentos políticos tradicionais. Que esse "efeito associativo" deriva de questões estruturais que transcendem as particularidades locais fica evidente ao vê-lo operar em situações bem diversas, sob distintos estilos de governo autoritários ou democráticos - e sob o auspício de distintos tipos de políticas - "populistas" ou "desenvolvimentistas" (como no caso do México até os anos 80) ou "neoliberais". ${ }^{26}$

O exercício realizado até aqui compartilha com muitos outros trabalhos uma perspectiva inspirada na recusa de tratar a distinção legal/ilegal e formal/informal como esferas ou universos existentes fora das definições e distinções que os estruturam (De Genova 2002; Cunha 2006; Telles 2009). Precisamente, é no trabalho de definição e de distinção que essas dicotomias se constituem como dimensões sociais relevantes e significativas.

A categoria ilegalismo, introduzida por Michel Foucault (1989 [1975]: 80 e segs.), é particularmente relevante para dar conta dessa perspectiva, uma vez que remete à gestão diferencial em torno das ilegalidades praticadas em determinado momento: tolerando essas, apertando aquelas, castigando outras. ${ }^{27}$ Um dos eixos explorados por Foucault, em Vigiar e Punir, para dar conta do nascimento da prisão é, precisamente, a transformação na gestão dos ilegalismos em finais do século XVIII, centrada, por um lado, na perseguição movida por "tribunais ordinários e castigos" aos ilegalismos mais acessíveis às classes populares - os ilegalismos dos bens, i.e., o roubo - e, por outro lado, na tolerância, a partir de "[...] jurisdições especiais, com transações, compromissos, e multas atenuadas, etc.”, em relação aos ilegalismos dos direitos reservados à burguesia - i.e., fraude, evasão fiscal, operações comerciais irregulares (Foucault 1989 [1975]: 91). ${ }^{28}$ Nessa nova configuração, segundo o autor, a prisão “[...] tem sido um instrumento para reorganizar o campo dos ilegalismos” (1994b [1976]: 93).

26 Além do México dos anos 90, este último tipo de políticas evidencia-se no caso dos vendedores de rua de Bridgetown (Barbados), onde o chamado por uma associação forte e representativa por parte das autoridades governamentais é uma das exigências do Estado para fazer cumprir seus planos de reordenamento urbano, baseados em uma reconversão inspirada nos planos de estabilização do Fundo Monetário Internacional (Cutsinger 2000). Junto com outros pesquisadores, estou realizando um levantamento das pesquisas sobre vendedores de rua - os chamados camelôs - no Rio de Janeiro e no Brasil em geral, constatando-se o mesmo fenômeno em todos os casos até agora analisados.

27 Illégalisme foi traduzido nas versões em português e inglês da obra de Foucault (1989 [1975]) como "ilegalidade", desconsiderando o esforço conceitual em estabelecer uma categoria diferenciada dos conceitos de legal e ilegal.

28 Tal como Foucault explicaria em uma conferência proferida logo após o lançamento de Vigiar e Punir, “[...] Todo dispositivo legislativo dispôs espaços protegidos e aproveitáveis em que a lei pode ser violada, outros em que pode ser ignorada, outros enfim, em que as infrações são sancionadas [...] No final das contas, diria que a lei não é feita para impedir tal ou tal tipo de comportamento, mas para diferenciar as maneiras de contornar a própria lei” (Foucault 1994a [1975]: 719 - tradução minha). Para uma análise da noção de ilegalismo, ver Fonseca (2002: 130 e segs.). Para uma utilização no sentido aqui conferido e aplicada a um universo similar, ver Telles (2009). 
No meu trabalho sobre a fronteira entre Brasil e Paraguai, corriqueiramente retratada por meios de comunicação, agências governamentais e pesquisas acadêmicas como um buraco de ilegalidades, a noção de ilegalismo foi fundamental. Ela me ajudou a compreender as práticas de comerciantes e sacoleiros, de importadores e traficantes, de laranjas e empregados dentro de um quadro definido pela lei mas gerenciado de forma diferencial: o espaço das possibilidades e das desigualdades, da implementação certeira e das tolerâncias regulares.

Contudo, o material mesitero oferece um outro ângulo para pensar sobre os ilegalismos, não já centrado na gestão das ilegalidades per se, mas no papel que tem a própria lei na produção de universos reconhecidos, porém produzidos de forma tal que garantem a reprodução da possibilidade de intervenções e repressão. Na impossibilidade de conciliar os processos políticos que tornam possíveis as leis e os procedimentos que elas instauram, se reproduzem as condições de novas precariedades e ilegalidades.

Desde as imaculadas páginas dos códigos e posturas municipais, as leis e as regulamentações aparecem com uma coerência que não somente é colocada em questão na gestão diferencial das ilegalidades, como também na sua própria produção. E aqui cabe perguntar-se: será que somente a regularização das denominadas "categorias de trabalho informal" estão emaranhadas nas inconsistências e contradições apresentadas até aqui?

Além da gestão das ilegalidades, também precisamos prestar atenção às práticas de regulamentação efetivamente praticadas como forma de desconstruir o operador que define legalidades e ilegalidades e, quem sabe, como forma de abrir novos caminhos para muitas das experiências que lutam pela possibilidade de serem realizadas sem perseguições ou extorsões.

\section{BIBLIOGRAFIA}

AMARAL, Arthur Bernardes de, 2010, A Tríplice Fronteira e a Guerra ao Terror. Rio de Janeiro, Apicuri.

BAER, Werner, e Melissa H. BIRCH, 1984, "Expansion of the economic frontier: Paraguayan growth in the 1970s", World Development, 12 (8): 783-798.

BARTOLOMÉ, Mariano César, 2002, "La triple frontera: principal foco de inseguridad en el Cono Sur americano," Military Review (Hispano-American), 82 (4): 61-74.

CASTRO NIETO, Guillermina G., 1990, "Intermediarismo político y sector informal: el comercio ambulante en Tepito", Nueva Antropología, XI (37): 59-69.

CROSS, John C., 1998, Informal Politics: Street Vendors and the State in Mexico City. Standford, CA, Standford University Press. 
CUNHA, Manuela Ivone P. da, 2006, "Formalidade e informalidade: questões e perspectivas," Etnográfica, 10 (2): 219-231.

CUTSINGER, Loran E., 2000, "Tips of trade: street vendors and the State in Barbados, West Indies”, International Journal of Sociology and Social Policy, 20 (3/4): 64-75.

DE GENOVA, Nicholas P., 2002, "Migrant 'illegality' and deportability in everyday life", Annual Review of Anthropology, 31: 419-444.

DUNEIER, Mitchell, 1999, Sidewalk. Nova Iorque, Farrar, Straus and Giroux.

FONSECA, Márcio Alves da, 2002, Michel Foucault e o Direito. São Paulo, Editora Max Limonad. FOUCAULT, Michel, 1989 [1975], Vigilar y Castigar: Nacimiento de la Prisión. Buenos Aires, Siglo Veintiuno Editores.

_ 1994a [1975], "Des supplices aux cellules" (entrevista com R.P. Droit), em Dits et Écrits. Paris, Gallimard, vol. II, 716-720.

_, 1994b [1976], "Points de vue," em Dits et Écrits. Paris, Gallimard, vol. III, 93-94.

GEERTZ, Cliford, 1977, "Centers, kings, and charisma: reflections on the symbolics of power", em Ben-David e Terry Nichols Clark (orgs.), Culture and Its Creators: Essays in Honor of Edward Shils. Chicago e Londres, The University of Chicago Press, 150-171.

JHABVAla, Renana, 2000, "Roles and perceptions", Seminar, 491 (Street vendors: a symposium on reconciling people's livelihood and urban governance), disponível em <http://www.india-seminar.com/2000/491/491\%20r.\%20jhabvala.htm> (acesso em 05/09/2003).

KARAM, John Tofik, 2010, "Atravesando las Américas: la 'guerra contra el terror', los árabes y las movilizaciones transfronterizas en Foz do Iguaçu y Ciudad del Este,” em Verónica Giménez Béliveau e Silvia Montenegro (orgs.), La Triple Frontera: Dinámicas Culturales y Procesos Transnacionales. Buenos Aires, Espacio Editorial, 112-127.

MACGAFFEY, Janet, e Rémy BAZENGUISSA-GANGA, 2000, Congo-Paris Transnational Traders on the Margin of the Law. Oxford, Bloomington e Indianápolis, James Currey e Indiana University Press.

MADANI, Blanca, 2002, "Hezbollah's global finance network: the triple frontier", Middle East Intelligence Bulletin, 4 (1), disponível em <www.meib.org/articles/0201_12.htm> (acesso em 06/06/2003).

MENDEL, William W., 2002, "Paraguay's Ciudad del Este and the new centers of gravity," Military Review, 82 (2): 51-58.

MONTENEGRO, Silvia, e Verónica G. BÉLIVEAU, 2006, La Triple Frontera: Globalización y Construcción del Espacio. Buenos Aires, Miño y Dávila Editores.

MORALES, Alfonso, 2000, "Peddling policy: street vending in historical and contemporary context", International Journal of Sociology and Social Policy, 20 (3/4): 76-98.

NATTRASS, Nicoli Jean, 1987, "Street trading in Transkei: a struggle against poverty, persecution, and prosecution", World Development, 15 (7): 861-875.

NESVÅG, Stein Inge, 2000, "Street trading from Apartheid to Post-Apartheid: more birds in the cornfield?", International Jounal of Sociology and Social Policy, 20 (3/4): 34-63.

RABOSSI, Fernando, 2004, Nas Ruas de Ciudad del Este: Vidas e Vendas num Mercado de Fronteira. Rio de Janeiro, UFRJ, tese de doutorado em Antropologia Social.

—, 2007, "Árabes e muçulmanos em Foz do Iguaçu e Ciudad del Este: notas para uma re-interpretação”, em G. Seyferth, H. Póvoa, M.C. Zanini e M. Santos (orgs.), Mundos em Movimento: Ensaios sobre Migrações. Santa Maria, Editora da Universidade Federal de Santa Maria, 287-312. 
RABOSSI, Fernando, 2008, En las Calles de Ciudad del Este: Una Etnografía del Comercio de Frontera. Assunção, CEADUC.

— - 2010a, "Cómo pensamos la Triple Frontera?”, em Verónica Giménez Béliveau e Silvia Montenegro (orgs.), La Triple Frontera: Dinámicas Culturales y Procesos Transnacionales. Buenos Aires, Espacio Editorial, 21-45.

—, 2010b, "Unidades, interações e representações fronteiriças: notas a partir da Tríplice Fronteira entre Brasil, Paraguai e Argentina”, em Edgar Aparecido da Costa, Gustavo Villela Lima da Costa e Marco Aurélio Machado de Oliveira (orgs.), Estudos Fronteiriços. Campo Grande, Editora UFMS, 113-144.

RAJAGOPAL, Arvind, 2002, "Violence of commodity aesthetics: hawkers, demolition raids and a new regime of consumption", Economic and Political Weekly, disponível em <http://www. epw.org.in/showArticles.php? $\operatorname{root}=2002 \&$ leaf $=01 \&$ filename $=3906 \&$ filetype $=\mathrm{html}>$ (acesso em 29/10/2004).

SHARMA, R.N., 2000, "The politics of urban space", Seminar, 491 (Street vendors: a symposium on reconciling people's livelihood and urban governance), disponível em <http://www.india-seminar.com/2000/491/491\%20r.n.\%20sharma.htm> (acesso em 05/09/2003).

SOTUYO, Patricia C. Godoy, 1998, Segregação Urbana: Estudo de Caso das Vilas de Itaipu. Florianópolis, UFSC, dissertação de mestrado em Geografia.

SOUZA, Edson Belo C. de, 2008, A (Re)produção da Região do Lago de Itaipu. Cascavel, Editora Coluna do Saber.

STOLleR, Paul, 2002a, "Crossroads: tracing African paths on New York City streets", Ethnography, 3 (1): 35-62.

— 2002 b, "Marketing afrocentricity: Western African trade networks in North America", Etnográfica, VI (1): 159-179.

TELLES, Vera da Silva, 2009, "Nas dobras do legal e do ilegal: ilegalismos e jogos de poder nas tramas da cidade”, Dilemas: Revista de Estudos de Conflito e Controle Social, 5-6: 97-126.

USATRADE, 2001, "Leading sectors for US exports and investments", em Country Commercial Guide: Paraguay, disponível em <http://www.usatrade.gov/website/CCG. nsf/CCGurl/CCGPARAGUAY2001-CH-5:-0063F769> (acesso em 05/10/2003).

VARCIN, Recep, 2000, "Competition in the informal sector of the economy: the case of market traders in Turkey", International Journal of Sociology and Social Policy, 20 (3/4): 5-33.

\footnotetext{
Negotiations, associations and monopolies: street politics in Ciudad del Este (Paraguay) - Fernando Rabossi • IFCS-UFRJ, Brasil • rabossi@rocketmail.com

Although there are municipal ordinances that regulate street vending in Ciudad del Este (Paraguay) and that the vendors seem to abide by them, the way the spaces for sale on the streets are occupied reveals a series of agreements, sedimentations and tolerances that are the basis of a system that reproduces the precariousness in which street vendors work. By exploring the ethnographic, historical and analytical contradictions between formal and practical ways of regulation, this article seeks to identify some recurrent mechanisms in the regularization of informal workers.
}

KEYWORDS: street vendors, associations, monopolies, trade, Paraguay, illegalism. 